\title{
A rare case of pregnancy with Sturge-Weber syndrome
}

\section{Ankita Pandey*, Prasad Yeshwant Deshmukh, Balaji Jadhav, Y. S. Nandanwar}

Department of Obstetrics \& Gynaecology, LTMMC \& GH, Sion, Mumbai, Maharashtra, India

\author{
Received: 11 March 2015 \\ Revised: 11 April 2015 \\ Accepted: 18 April 2015 \\ *Correspondence: \\ Dr. Ankita Pandey, \\ E-mail: sonamnrs86@gmail.com
}

Copyright: (C) the author(s), publisher and licensee Medip Academy. This is an open-access article distributed under the terms of the Creative Commons Attribution Non-Commercial License, which permits unrestricted non-commercial use, distribution, and reproduction in any medium, provided the original work is properly cited.

\begin{abstract}
Sturge-Weber syndrome is a rare sporadic neurocutaneous syndrome characterized by facial angiomas, ocular abnormalities (glaucoma and choroidal hemangioma), and leptomeningeal angioma. We report a case of Sturge Weber syndrome type I, associated with seizures, with gestational diabetes. She had successful labour outcome. Very few such cases have been reported in literature. The effect of pregnancy on neurological symptoms of Sturge Weber syndrome is not known.
\end{abstract}

Keywords: Sturge-Weber syndrome, Angioma, Glaucoma, Leptomeningeal angioma, Calcifications, Facial haemangioma

\section{INTRODUCTION}

Sturge Weber syndrome is a rare entity with incidence of 1 in every 50000. It is also called as encephalo trigeminal angiomtosis as the angiomatosis typically involve the distribution of leptomeninges and supply area of $1^{\text {st }}$ and $2^{\text {nd }}$ division of trigeminal nerve. Most commonly it involves the area supplied by $1^{\text {st }}$ division of trigeminal nerve. ${ }^{1}$ The facial port wine stain is associated with $3 \%$ cases of Sturge Weber syndrome. During $6^{\text {th }}$ week of intrauterine life, a vascular plexus develops around neural tube which develops into face in future. By $9^{\text {th }}$ week of gestation, usually it disappears. In case, it persists, it develops into future Sturge Weber syndrome. It can be classified as complete and incomplete depending on presence of facial and leptomeningeal angioma. Roache has further classified it as type I, type II, type III. ${ }^{2}$

Type I - Both facial and leptomeningeal angioma present, may have glaucoma.
Type II - Facial angioma only, no CNS involvement; may have glaucoma.

Type III - Only leptomeningeal angioma (CNS involvement); usually no glaucoma.

\section{CASE REPORT}

We present a case of 30 year old primigravida with 9 months amenorrhoea as known case of epilepsy since childhood with gestational diabetes mellitus at 36 weeks gestation

She had no episode of seizures since her conception as she was on tab. eptoin $100 \mathrm{mg}$ twice a day.

She was diagnosed GDM at around 10 weeks gestation and started on inj. insulin 6 units twice a day. Her sugar levels are well controlled. Patient was compliant and has maintained her records well. 
Her past history revealed that she had several episodes of seizure. When she was 2 year old child, she had received symptomatic treatment but diagnosis wasn't conclusive

She didn't have any episode of seizure uptill 15 years of age when she started having several episodes of seizure (GTCS) frequently and reported to hospital casualty often.

Detail investigations were done as:

Examination: Right V1 territory portwine stain present

Bilateral end gaze nystagmus present. Fundus normal. Hemiplegic migraine present

CT brain (plain) reported curvilinear calcifications in Gyral pattern involving right occipital lobe.

MRI brain (plain) reported choroid plexus in the right ventricle is markedly enlarged probably shows calcification. Curvilinear altered signal in the right occipital region which represents calcification with adjacent gliotic changes.

MRI brain (contrast) right parietooccipital choroid plexus angioma.

EEG was normal.

Patient was started on lifelong antiepileptic drugs.

Patient gives history of last episode of seizure in November 2013.

Patient gives no history of learning disabilities, paralysis, glaucoma, or stroke.

No history of headache, fever, cough or cold.

No history of hypoglycemic symptom reported yet.

Last menstrual period was 06/06/2014 and expected date of delivery was 13/03/2015.

On examination, general condition was found stable. Right side of forehead over entire V1 area portwine stain present. Systemic examination was normal.

On per abdominal examination, uterus corresponding to 38 weeks, relaxed.

Fetal heart sound present 144/min.

On per vaginal examination, os closed, cervix soft posterior.

Fundoscopy: No abnormality detected.
Rest all routine antenatal investigations were within normal limits.

Patient underwent caesarean section under general anaesthesia at 38 weeks of gestation with no complications. Elective caesarean section was conducted in view of maternal request for precious pregnancy. The baby was a female baby of $3.6 \mathrm{~kg}$ and cried immediately after birth.

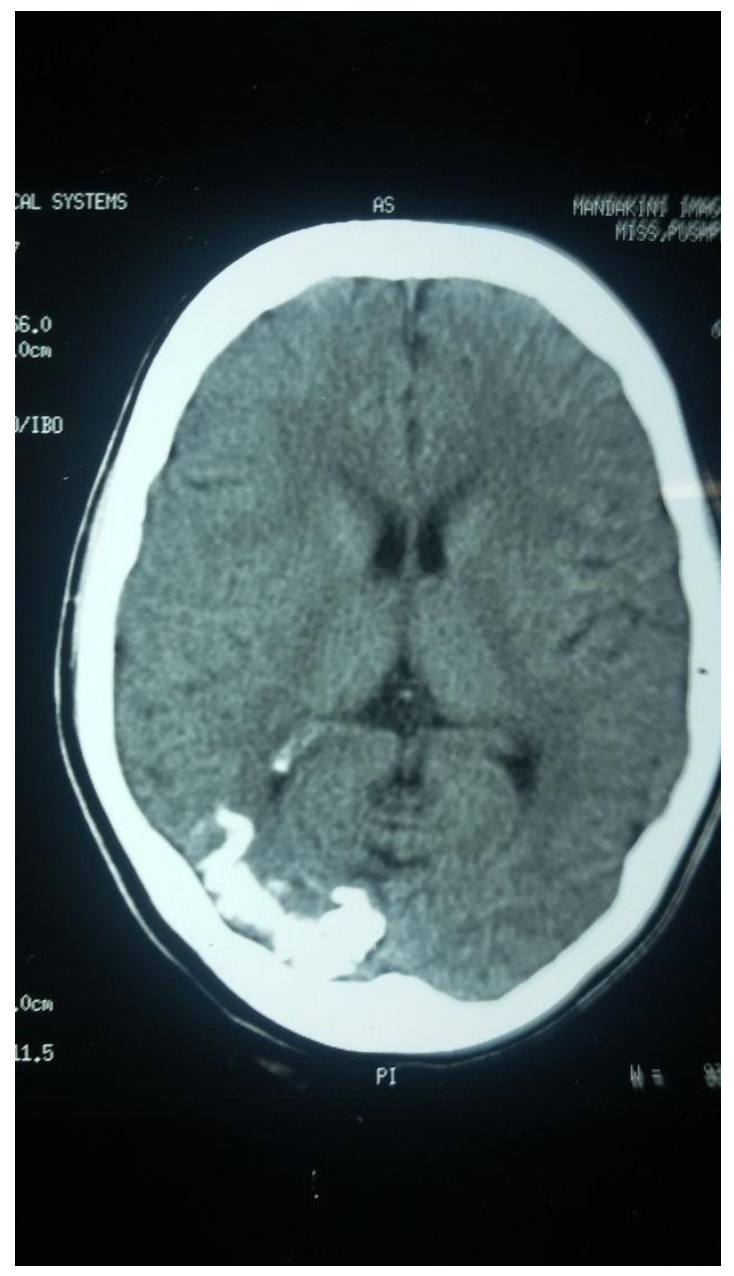

Figure 1: MRI brain showing haemangioma on parieto occipital cortex of right cerebral hemisphere.

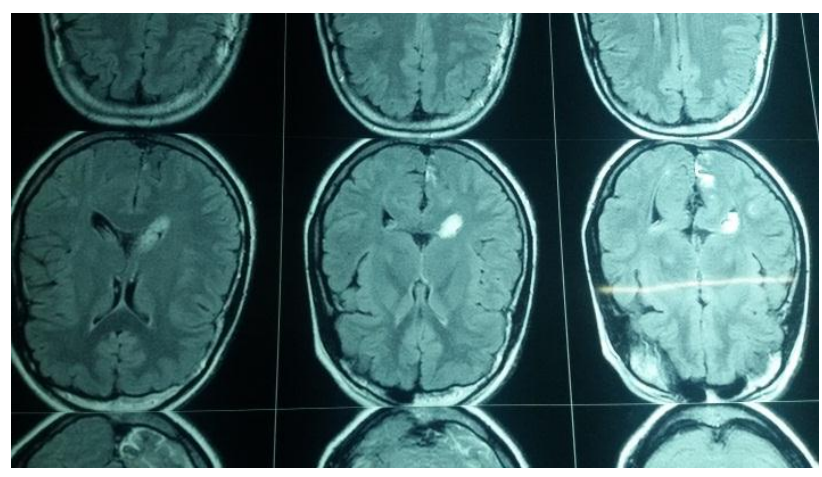

Figure 2: MRI Brain showing choroid plexus haemangioma of right lateral ventricle). 


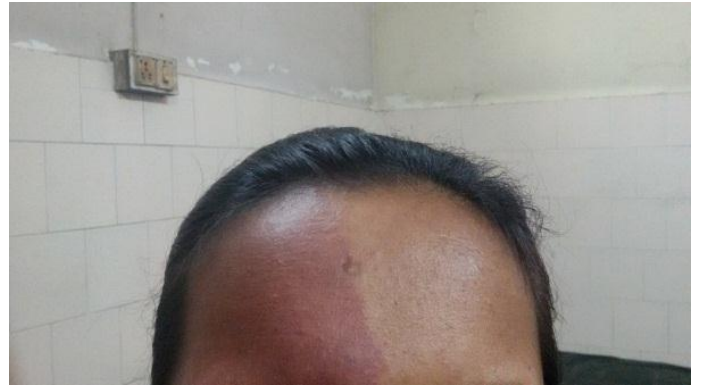

Figure 3: Port wine stain in region of right trigeminal nerve first division.

\section{DISCUSSION}

The case presented herewith belongs to type I Sturge Weber syndrome, as the patient had facial as well as leptomeningeal angioma. However, glaucoma was not present. Skin manifestation is portwine stains. Not all people with a port wine stains have Sturge Weber syndrome. The incidence of Sturge Weber syndrome with angioma in the area of $1^{\text {st }}$ division of trigeminal nerve is almost $70 \%{ }^{3,4}$ In SWS the leptomeningeal angiomatosis is predominantly venous and deep arterial malformations are uncommon. Cerebral venous malformations are considered relatively benign during pregnancy and they infrequently bleed during labor or in postpartum period. Cerebral arteriovenous and arterial haemangiomas are more dangerous and may rupture with blood pressure fluctuations and valsalva efforts during labor. ${ }^{5}$

Neurological manifestations are variable ranging from simple seizures to status epilepticus, that occur due to irritation caused by haemangioma to cerebral cortex. They can start manifesting at any age from childhood to 20 years.

There is a documentation of a patient with Sturge Weber syndrome who has undergone a near total hemispherectomy with subsequent cerebral palsy going on to have two successful and uncomplicated pregnancies. It is likely that having excellent clinical stability and high functional status after definitive treatment for Sturge Weber syndrome as a child significantly lowered the pregnancy-associated risks for patient. ${ }^{6}$ There are specifications about anaesthesia given during caesarean section as well. That it should not increase the intracranial tension. Hence, usually a lumbar epidural block is administered. ${ }^{7}$

\section{CONCLUSION}

Neuroimaging Maximum extent of disease may require a combination of structural and fuctional neuroimaging, since mismatch may exist among neuroimaging modalities. Each modality may demonstrate abnormalities not detected by the other. This is especially important in the identification of the epileptogenic region when considering surgery for refractory seizures. Medical management consists of antiepileptic medications started under cover of folic acid and calcium, in order to prevent foetal congenital anomalies. Glaucoma medications can be started only after consulting ophthalmic surgeon. In newborns, who present with portwine stain in $1^{\text {st }}$ division of trigeminal nerve should be subjected to detailed Ophthalmological examination in $1^{\text {st }}$ month of life and detailed neurological examination subsequently.

In cases where neurological deficit occurs, surgical extirpative procedures like hemespherectomy, cortical resection have been described. However, their risk benefit ratio has to be calculated before embarking on such procedures. In adult life, owing to calcification of sulci and gyri, there is every possibility of severe learning disability, which can only be overcome by special education for such children.

\section{Funding: No funding sources \\ Conflict of interest: None declared \\ Ethical approval: Not required}

\section{REFERENCES}

1. Baselga E. Sturge-Weber syndrome. Semin Cutan Med Surg. 2004;23(2):87-98.

2. Roach ES. Neurocutaneous syndromes. Paediatr Clin North Am (Medline). 1992;39(4)591-620.

3. Takeoka M. Paediatric Sturge Weber Syndrome clinical presentation, Medscape, 2010. Available at: http://emedicine.medscape.com/article/1177523clinical. Accessed 20 May 2013.

4. Hennedique AA, Quabe AA, Al-Nakib K. Sturge Weber Syndrome \& dermatological facial portwine stains; incidence, association with glaucoma and pulse tunable dye laser treatment effectiveness. Plast Reconstruc Surg. 2008;12(4):1173-80.

5. Gupta, Saini. Pregnancy with Sturge Weber syndrome presenting as status epilepticus. Indian J Med Case Rep. 2013 Apr-Jun;2(2):19-22.

6. Aziz AS, Hui D, Chinnappa V, Aviv RI, Swartz RH. Successful pregnancy, epidural anaesthesia, labour and delivery in a woman of Sturge Weber syndrome with previous hemespherectomy. J Obstet Gynaecol Can. 2013;35(10):917-9.

7. Tadrous R, Ni Mhuirchteagh $\mathrm{R}$, McCaul C. Anaesthesia for caesarean section in a patient with Sturge-Weber syndrome following acute neurological deterioration. Int $\mathrm{J}$ Obstet Anesth. 2011;20(3):259-62.

DOI: $10.18203 / 2320-1770 . i j r c o g 20150112$

Cite this article as: Pandey A, Deshmukh PY, Jadhav

B, Nandanwar YS. A rare case of pregnancy with

Sturge-Weber syndrome. Int J Reprod Contracept

Obstet Gynecol 2015;4:866-8. 